\title{
Molecular Detection and Pathology of Necrotic Enteritis Case from a Guinea Fowl
}

\author{
S. Rathnapraba ${ }^{1 *}$, Kannabhiran $^{1}$, P. Kanagaraju ${ }^{2}$, K. Vijayarani ${ }^{1}$ and S. Saranya ${ }^{1}$ \\ ${ }^{1}$ Department of Animal Biotechnology, ${ }^{2}$ Department of Poultry Science, Madras Veterinary \\ College, Tamilnadu Veterinary and Animal Sciences University, Chennai-07, India \\ *Corresponding author
}

\section{A B S T R A C T}

Necrotic enteritis is an important bacterial disease of poultry caused by type A and type C of the enteric gram positive spore forming organism Clostridium perfringens. Necrotic enteritis suspected case was presented for necropsy from a dead guinea fowl. Gross

Keywords

Guinea fowl, mPCR, Necrotic enteritis, Toxin genotyping.

Article Info

Accepted: 29 May 2017 Available Online: 10 June 2017 examination showed ulcerative lesions in the intestine. Microscopically, necrosis and degeneration of the intestinal villi and mononuclear cell infiltration was noticed. Liver histopathology revealed that the mononuclear cells infiltration and perivascular cuffing in blood vessels. The causative organism was isolated from the intestinal contents under anaerobic condition. The collected sample was processed and growth was achieved on tryptose - sulphite - cycloserine (TSC) agar, blood agar, clostridial agar, perfringens agar. Typical Clostridium perfringens colonies were identified by grams staining and further confirmed by biochemical characterization. For molecular confirmation genomic DNA was isolated from $C$. perfringens and amplified using 16s rRNA universal primer. Multiplex PCR (mPCR) was carried out for toxin genotyping and the isolate was found positive for $\alpha$ toxin (cpa), a characteristic feature of $C$. perfringens type A. The present report emphasizes the molecular characterization and toxin genotyping as a rapid tool for detection of $C$. perfringens from suspected necrotic enteritis cases in poultry.

\section{Introduction}

Necrotic enteritis is caused by an anaerobic gram positive, spore forming bacteria Clostridium perfringens type A and to a lesser extent the type C (Cooper and Songer, 2009). It is often found in the intestinal tract of healthy broiler chickens but it can cause necrotic enteritis (NE) in many species of poultry (Engstrom et al., 2003). The disease primarily affects broilers 2-6 weeks of age and turkeys 7-12 weeks of age. However NE has been reported in Japanese quails and other fowls raised on litter.
The clinical illness is usually very short and often the only signs are severe depression followed quickly by a sudden increase in flock mortality.

The present study reports the isolation, identification, pathology and molecular detection of the causative organism $C$. perfringens causing necrotic enteritis in a guinea fowl, by $16 \mathrm{~s}$ rRNA PCR followed by multiplex PCR for toxin genotyping. 


\section{Materials and Methods}

An adult 8 week old dead female guinea fowl was necropsied at Poultry Research Station, Tamil Nadu Veterinary and Animal Sciences University, Madhavaram, Chennai and the sample was used for further processing. History revealed that the affected bird showed signs of in appetence, diarrhoea and debility. Samples were collected aseptically including intestinal contents, liver and intestinal scrappings for bacteriological examination and isolation of the organism. The tissues samples were processed for histopathological studies.

\section{Isolation of Clostridium perfringens and PCR confirmation}

For isolation of Clostridium perfringens, strict anaerobic conditions were maintained. Sterile saline was added to the intestinal contents of the sample and heated at $80^{\circ} \mathrm{C}$ for $20 \mathrm{~min}$ in water bath. Then the processed intestinal contents were inoculated into fluid thioglycollate broth, reinforced clostridial broth, Robertson cooked meat medium with brain heart infusion broth and incubated in anaerobic environment at $37{ }^{\circ} \mathrm{C}$ for $48 \mathrm{~h}$. About $100 \mu \mathrm{l}$ of the culture suspension was placed into sterile Petri dish and overlaid with tryptose-sulphite-cycloserine (TSC) agar with selective supplement for perfringens (Himedia Pvt. Ltd., Mumbai) and without egg yolk emulsion for morphological characterization.

Further, samples from the broth also were streaked on the perfringens agar plate enchanted with egg yolk emulsion (EYA agar). To maintain anaerobic condition, plates were sparged with $\mathrm{CO}_{2}$ gas and then sealed using parafilm. All the incubations were conducted in anaerobic chamber with anaerogas pack (Himedia Pvt. Ltd., Mumbai). DNA was extracted from the bacterial culture using DNA extraction kit (Quiagen, USA) as per the manufacturer's instructions. The $C$. perfringens suspected DNA samples were amplified using 16s rRNA universal primer as follows $16 \mathrm{~s} \quad \mathrm{rRNA} \quad \mathrm{F}$ AGAGTTTGATYMTGGC and 16s rRNA R - GYTACCTTGTTACGACTT (Davies et al., 1996).

For amplification, a $25 \mu 1$ reaction mixture was prepared with $1.0 \mu \mathrm{l}$ (10 picomole) of each primer, $12.5 \mu 1$ of PCR master mix (Ampliqon), $2.0 \mu 1$ of genomic DNA and 8.5 $\mu 1$ of nuclease free water. The amplified PCR product was confirmed by $1.5 \%$ agarose gel electrophoresis. Specific amplicon was purified using QIA quick Gel extraction kit and then sequenced in Leads India Pvt. Ltd., Kochi. Further, the sequences were aligned, assembled and analyzed by DNA Star Laser gene V. 7.0 software.

Toxin genotyping of the isolate was carried out by multiplex PCR targeting three major toxin genes cpa, cpb, cpe as described previously (Baums et al., 2004).

\section{Results and Discussion}

Clostridium perfringens, the causative agent of necrotic enteritis was isolated and identified from a clinical case of guinea fowl. Gross examination revealed that pathological changes in the intestinal segments. The intestinal mucosa showed several oval to elongated necrotic to ulcerative lesions with raised hyperemic borders (Figure 1a). There are no significant pathological lesions in the other visceral organs were observed. Histopathological lesions showed the partial or complete damage of villi in the necrosis areas with mononuclear cell infiltration (Figure 1b) as reported earlier (van Immerseel et al., 2009). Histopathology of liver showed congestion and mononuclear cell infiltration. 
Bacterial colony morphology on blood agar showed a clear double zone of haemolysis that was similar to the findings of earlier report (Craven et al., 2001; Malmarugan and Rajeswar, 2012). Yellowish grey colonies were observed in TSC agar with egg yolk supplementation (Figure 2a). The colonies on perfringens agar supplemented with egg yolk agar were identified by a typical opalescence around the colonies as in figure $2 \mathrm{~b}$. The lipoprotein component lecithovitellin in egg yolk agar is split by lecithinase into phosphoryl choline and an insoluble diglyceride, which results in the formation of a precipitate in the medium. The precipitate occurs as a white halo, surrounding the colony producing it. The alpha toxin of C. perfringens produces lecithinase and hence white zone was indicative of $C$. perfringens strain containing alpha toxin. The findings of opalescence colonies in egg yolk suggestive of Clostridium and the observation was in agreement with the previous report (Barrow and Feltham, 1993).

Fig.1 Histopathological changes in (a) intestinal villi damage (b) mononuclear cell infiltration
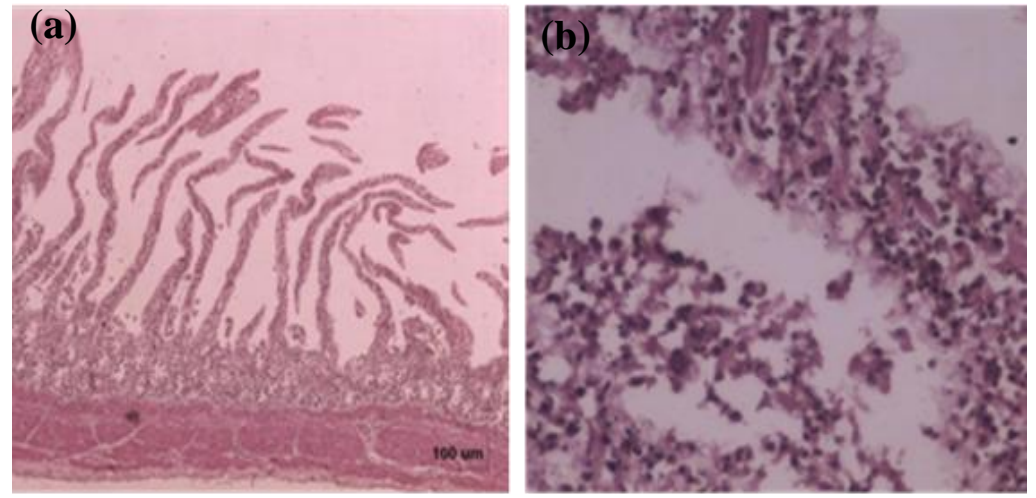

Fig.2 Growth pattern of Clostridium perfringens $\mathbf{a}$. Yellowish grey colonies in TSC agar; $\mathbf{b}$. Opalescent zone around the colonies due to lecithinase activity in egg yolk agar
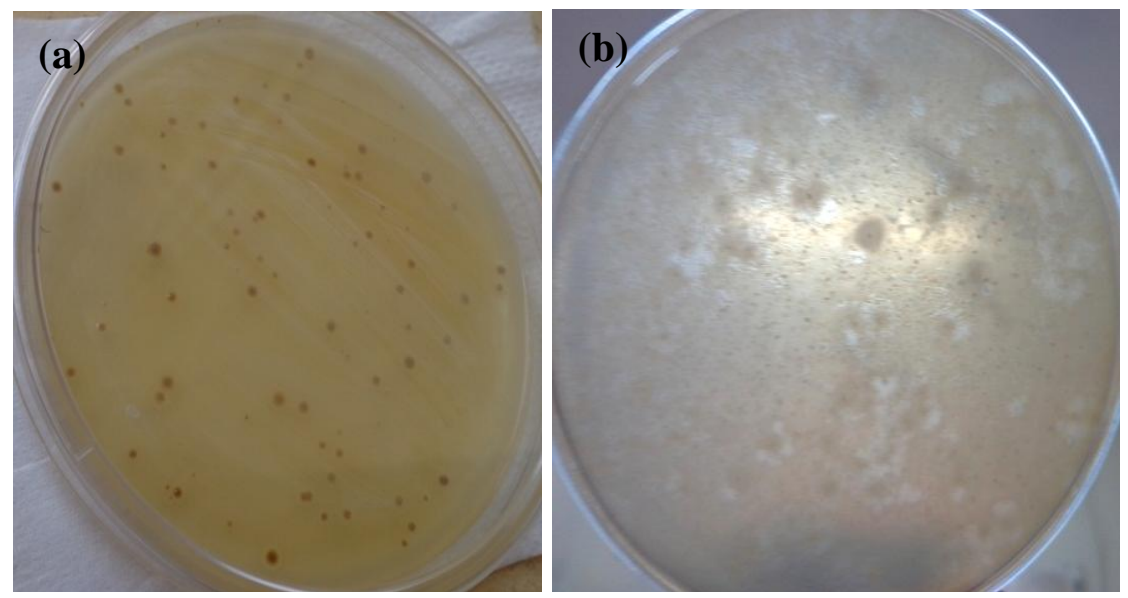
Fig.3 1.5\% agarose gel showing 16srRNA gene amplification. Lane 1 - 100 bp ladder; Lane 2-994 bp 16srRNA gene

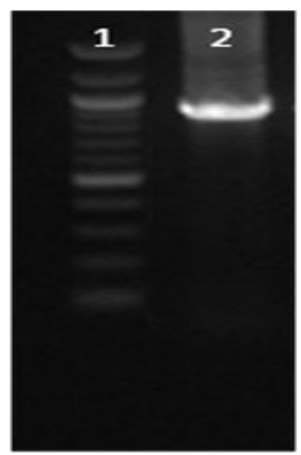

994bp

Fig.4 1.5\% agarose gel showing amplification of cpa toxin gene. Lane 1-100bp ladder; Lane 2-900 bp cpa toxin gene amplicon

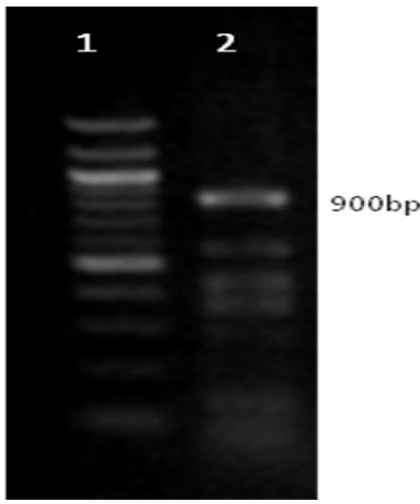

PCR amplicons of $994 \mathrm{bp}$ were noticed on $1.5 \%$ agarose gel (Figure 3) and further confirmed by sequencing. Blast analysis showed that sequence had $93 \%$ homology when compared with the reference sequence of $C$. perfringens (AB566417.1) available in the genbank.

Multiplex PCR for toxin genotyping of $C$. perfringens was positive for $900 \mathrm{bp}$ cpa toxin gene PCR amplicon (Figure 4), a feature indicative of $C$. perfringens type A isolate. It is well documented that $\alpha$ toxin producing $C$. perfringens is more common in intestinal microbiota of diseased chicken.

And our result suggested that the prevalence of type A, C. perfringens in the intestine of poultry species with necrotic enteritis harboring the $\alpha$-toxin gene as predominant toxinotype similar to the previous reports of Engstrom et al., (2003) and Thomas et al., (2014) in broiler and Kadakanath fowl respectively.

This paper reports the isolation and identification of $C$. perfringens, causing necrotic enteritis in a guinea fowl. Molecular detection, characterization by 16s rRNA gene sequencing and toxin genotyping by multiplex PCR were utilized for rapid detection and confirmation of $C$. perfringens from the suspected case.

\section{References}

Barrow, G. I., and Feltham, R. K. A. 1993. Cowans and Steel's Manual for 
identification of medical bacteria. $3^{\text {rd }}$ ed., Cambridge University Press, pp.331.

Baums, C. G., U. Schotte, G. Amsberg and Goethe, R. 2004. Diagnostic multiplex PCR for toxin genotyping of Clostridium perfringens isolates. Veterinary Microbiology. 100: 11-16.

Cooper, K. K., and Songer, J. G. 2009. Necrotic enteritis in chickens: A paradigm of enteric infection by Clostridium perfringens type A. Anaerobe. 15: 55-60.

Craven, S. E., N. J. Stern, J. S. Bailey and Cox, N. A. 2001. Incidence of Clostridium perfringens in broiler chickens and their environment during production and processing. Avian Diseases. 45: 887-896.

Davies, C., V. Ramakrishnan and White, S. W. 1996. Structural Evidence for specific S8-RNA and S8 - protein interactions within the $30 \mathrm{~S}$ ribosomal subunit: ribosomal protein S8 from Bacillus stearothermophilus at $1.9 \AA$ resolution. Structure. 4: 1093-1104.
Engstrom, B. E., C. Fermer, A. Lindberg, E. Saarinen, V. Baverud and Gunnarsson, A. 2003. Molecular typing of isolates of Clostridium perfringens from healthy and diseased poultry. Veterinary Microbiology. 94: 225-235.

Malmarugan, S., and Rajeswar, J. 2012. Alpha toxin specific PCR for detection of toxigenic strains of Clostridium perfringens in Poultry. Veterinary World. 5(6): 365-368.

Thomas, P., T. R. Arun, K. Karthik, P. V. Berin, M. Ashok Kumar, Neethu Singh, J. Usharani, M. Palanivelu, S. K. Gupta, K. Dhama and Viswas, K. N. 2014. Molecular characterization and toxinotyping of a Clostridium perfringens isolate from a case of necrotic enteritis in Indian Kadaknath fowl. Asian Journal of Animal and Veterinary Advances. 9: 385-394.

Van Immerseel, F., J. I. Rood, R. J. Moore and Titball R. W. 2009. Rethinking our understanding of the pathogenesis of necrotic enteritis in chickens. Trends Microbiology. 17: 32-36.

\section{How to cite this article:}

Rathnapraba, S., Kannabhiran, P. Kanagaraju, K. Vijayarani and Saranya, S. 2017. Molecular Detection and Pathology of Necrotic Enteritis Case from a Guinea Fowl. Int.J.Curr.Microbiol.App.Sci. 6(6): 2589-2593. doi: https://doi.org/10.20546/ijcmas.2017.606.309 